M. Korber, M. Paier

\title{
R\&D NETWORKS AND REGIONAL KNOWLEDGE PRODUCTION: AN AGENT-BASED SIMULATION OF THE AUSTRIAN COMPETENCE CENTRES PROGRAMME
}

Publicly funded competence centres have gained high recognition for improving science-industry collaboration. With the requirement for long-term and geographically concentrated $R \& D$, competence centres provide an environment for joint learning and transfer of "sticky" knowledge. The objective of this paper is to investigate how a competence centres programme affects knowledge production in the regional innovation system. In order to address this issue, we draw on a simulation approach and develop an agent-based model of the Vienna Life Sciences innovation system. Companies, research organisations and universities are heterogeneous agents that create scientific publications, patents, as well as high-tech jobs. Simulation runs refer to long-term scenarios regarding the level and duration of public funding. By addressing the complexities of knowledge interaction in the context of the "local buzz" versus "global pipelines" discussion, the results show the potential of empirically calibrated simulation models for ex-ante impact assessment in R\&D policy.

Keywords: Competence centres; Public research funds; Science-industry collaboration; Agent-based simulation; Learning; Research \& Development; Ex-ante impact assessment

\section{Introduction}

There is broad agreement on the fact that innovation is necessary to achieve and sustain competitiveness of regions (e.g. [14]). In this regard, public funding for research and development is considered an important contribution to secure an effective and efficient regional innovation system, in the recent past increasingly shifting attention to the support of networking activities and collaborative knowledge production. However, evidence on effects of policy instruments supporting regional $\mathrm{R} \& \mathrm{D}$ networks on a region's innovative performance is scarce since the particular effects are attributable to specific policy interventions only to a very limited extent. The reason is that interventions in self-organized systems - like regional innovation systems - trigger effects, which are not easily predictable [17]. Small changes in subsystems might affect the overall system in different ways, ranging from no effect at all to the far-reaching system transitions. The research into self-organized systems investigates phenomena such as a non-linearity, path dependency, bifurcations and emergence. Such phenomena particularly challenge systematic empirical research on how policy-induced R\&D networks affect the performance of regional innovations systems, which is on top of the research agenda in economic geography and regional science.

This paper focuses on the effects of a specific type of a policy programme supporting geographically localised networking activities, the Austrian

${ }^{1}$ ( ) Korber M., Paier M. Text. 2014. competence centres programme. Competence centres are institutionalized research ventures that gather academic and industry partners at a certain location. These are dedicated to highlevel, application-oriented research on a particular topic of broad societal interest, thus aiming at critical mass and international visibility. This public funding scheme has a high relevance for the Austrian innovation system and draws on a considerable budget. All in all, EUR 675 million of public funds are devoted to the promotion of competence centres in the framework of the COMET $^{2}$ programme [44, pp. 3-7].

The objective of this paper is to investigate the effects of competence centres in a specific sectorial, regional context - the Vienna life sciences innovation system - on the evolution of knowledge output in the long run. Hereby, we apply agentbased modelling techniques to explore knowledge production in different long-term scenarios (30 years) regarding competence centre funding in an empirically calibrated model.

The model comprises a set of heterogeneous agents representing companies, research organisations and universities in the life sciences innovation system. They are able to create knowledge through own $R \& D$, exchange knowledge with others through $R \& D$ networks and other exchange mechanisms, and produce output using public and private funding sources. At this point, it is important to mention that agent-based simulation does not provide forecasts, but gives insights into basic

\footnotetext{
2 COMET (Competence Centers for Excellent Technologies) programme: funding period from 2008-2019.
} 
aspects of different scenarios. Thus, the simulation model can be seen as an experimental laboratory for testing policy measures ex ante. This has the potential to improve the current practice of relying mainly on past experience and expert knowledge, which is hardly able to avoid bias on individual perceptions and strategic behaviour.

The paper is organized as follows: The theoretical foundation of this paper is given in Section 2, which leads to the formulation of hypotheses regarding effects of competence centres. Section 3 is dedicated to the empirical test environment, i.e. the Vienna life sciences innovation system. The main components of the agent-based model are described in Section 4. Then, Section 5 presents details on the different simulation scenarios and their respective results. The paper closes with a discussion of the method, its limitations and an outlook on further research.

\section{Public funding of localised R\&D networks and regional knowledge production}

The importance of $R \& D$ cooperation for innovation in regions is well established in the scientific literature (e.g. [12; 16]. Regions have been attracting the interest of both scientists and policymakers as the designated sites of innovation and competitiveness. Numerous empirical studies have focused on regional clusters, starting with the famous success story of Silicon Valley [39]. Some clusters prosper, while others do not - the reasons for that difference in progress are still unclear [11, p. 24]. Studies on clusters usually draw on the common rationale that territorial agglomeration provides the best context for an innovation-based globalizing economy due to localized learning processes and "sticky" knowledge grounded in social interaction [3]. It is a general lesson from research on $R \& D$ networks that open and interconnected networks with links to different knowledge categories foster knowledge diffusion, exploit synergies, and bridge social closure [46].

R\&D networks provide channels for communication, interaction, and mutual knowledge exchange inside and beyond the regional boundaries, transcending sectors as well as industries. They facilitate collective learning and the exploitation of complementarities on the basis of non-market exchange relations, which are so important for the generation of novelty [36]. Thus, $\mathrm{R} \& \mathrm{D}$ networks are a prime vehicle to balance regional economic focus, technological specialization and diversity as sources of the innovative performance of the region and thus of its economic prosperity [24].
Competence centres are a special type of policy-induced R\&D networks as they gather academic and industrial partners in a certain location. They support the role of universities in applied research networks, not only as an important pool for highly skilled labour [26; 9, p. 2; 21, p. 40; 23, p. 957] but also as important partners for small and medium sized companies [32, 28]. Tacit knowledge can generally be referred to as a prime reason for cooperation [18, p. 346]. In this regard, competence centres support innovation by enabling access to implicit (or tacit) knowledge ${ }^{1}$ both geographically localized, but also to distant knowledge via internationally networked partners. Thus, competence centres can be regarded as public instrument to stimulate the combination of the local buzz vs. global pipelines structure for regional knowledge production. They may serve as additional levers to accelerate regional knowledge diffusion by supporting local networking augmented with channels to tap international knowledge sources, and, by this, foster overall regional innovation output.

Especially in the life sciences, industrial and academic agents operate in a dynamic environment characterised by fast-expanding scientific knowledge and scattered expertise. High development costs are often associated with long time lags in the commercialization of scientific results [13]. Therefore, agents operate under high uncertainty, and, in order to keep pace with innovation, they engage in research cooperation networks 35 , typically involving both small dedicated biotechnology firms and large diversified, often transnational, firms with access to global markets and world class academic institutions. The demand for tacit knowledge leads the organizations to cluster geographically and to engage in R\&D networks, especially relevant for small dedicated biotech firms [25]. We are thus led to expect that (regarding the number of SMEs and high-tech jobs) the SME sector benefits more from the competence centres programme than large companies do (Hypothesis 1).

The extraordinary importance of scientific knowledge in the life sciences is to a large extent associated with high collaboration intensity between academia and industry. Knowledge spillovers between scientific organizations and companies in cooperative projects as well as during co-publications are most intense if they are based on dense and frequent face-to-face contact [40]. Firms, which cooperate with universities are more often involved in basic research, they have access

\footnotetext{
${ }^{1}$ Tacit knowledge is uncodified, maybe even uncodifiable and varies individually (Fischer 2003, p. 345).
} 
to higher quality ideas and their invention process is more effective in general [15]. We therefore hypothesise that due to close scientific cooperation of companies and universities, the competence centres programme strongly favours regional patenting activity (Hypothesis 2).

According to recent research policy, universities are generally required to increase cooperation with industry partners. In this regard, worries arise regarding an undesired drift to applied research and, consequently, a decrease in publication output. On the other hand, empirical evidence has been produced indicating that researchers that accomplish both patenting and publication activities, are likely to produce more publications. In fact, even reinforcement effects of both activities have been observed [47]. Consequently, we expect that the number of publications in the region rises due to the existence of the competence centres programme (Hypothesis 3).

\section{Competence centres and the Vienna life sciences innovation system}

In the following, we give a brief overview of the life sciences innovation system in the Vienna region before we turn to the Austrian competence centres programme, which plays an important role therein. The mid-1980s saw the foundation of a joint venture of two large international firms, ${ }^{1}$ which sparked off dynamic activities in the life sciences sector in Vienna [22]. By 2011, more than 400 life sciences companies were located in Vienna, almost a quarter is involved in biotechnology and medical technology with 9,100 employees, generating about EUR 1.7 billion in sales (2010). 14,100 persons were employed in academic research for life sciences [30, pp. 3-7]. The Vienna life sciences innovation system is especially known for medical biotechnology such as oncology, immunology and neurobiology with expertise in analytical methods and services, diagnostics and diagnostic technologies, microbiology or pharmaceuticals. Another focus of life sciences in Vienna that gained momentum recently is the research on medical technology and devices [6].

From a policy perspective, funding activities specifically dedicated to the life sciences were rather underdeveloped until the late 1990s. Only in 1999, an Austrian biotech programme was introduced which has led to the setup of the life sciences cluster initiative in 2002 [29]. Since 2003, the focus of regional research policy lies on life sciences [49] and in 2004, more than five percent of the Austrian public research budget was invested

\footnotetext{
${ }^{1}$ These companies were Boehringer Ingelheim and Genentech.
}

in biotechnology, covering all parts of the innovation system with a combination of generic and biotech-specific instruments and a focus on education, research and fiscal policy ${ }^{2}$ [38, pp.74-75].

By 2004, science-industry linkages have been identified as the major weakness of the Austrian innovation landscape in international comparison [33]. First attempts to cope with this issue remained unsuccessful and only the new Austrian university law provided incentives for universities to engage in cooperative projects with industry partners [43]. The development of the competence centres programmes can be seen as a milestone in this regard, but also the increased number of thematic programmes made an important contribution. In this context, it is worth noting, that Austrian research policy in general emphasises indirect funding, i.e. tax incentives for research. Institutional funding is to a large extent used by universities, while the number of public non-profit research institutes is rather low compared with OECD countries. Almost fifty percent of the direct public funds are directed to cooperative research projects, particularly to competence centres [42, pp. 73-74].

Meanwhile, Austria's culture of cooperation is of high renown worldwide. A broad range of different public funding instruments aims at the promotion of science-industry relations, thus supporting the fast commercialization of scientific findings. Especially, the enlargement of technology and structural programmes since the 1990s has been important in this regard, and competence centres and networks are among the most prominent and successful examples of these funding measures. Companies play an essential role in knowledge and technology transfer, this is reflected even in a strong and sustainable increase in national $R \& D$ expenditures and provoked by an increasing number of researching firms and their respective research intensity [42, p. 81].

The Austrian competence centres programme aims at improving science-industry collaboration, the efficiency of industrial research and at building up human capital through a temporary boost of research endeavours. In its current make, the Austrian competence centres programme, COMET, comprises three different types of activities with increasing size, resource endowments and duration: The K-Projects, K1- and K2-Centres [44]. In K-Projects, running for 3-5 years, participation of at least one academic and three industrial partners

\footnotetext{
2 [38, pp. 74-75] used historical data (1994-2002) on policy activities and national performance in biotechnology and benchmarked data regarding biotech policies in the year 2004 .
} 
is required. These projects are 1 million EUR per year in maximum size and offer up to $45 \%$ public subsidy. K1-Centres support science-industry collaboration of at least one academic and five industrial partners. For a 7-year period, a maximum annual budget of 1.5 million EUR is foreseen with up to $50 \%$ public support. Compared with this, the K2-Centres are the largest and most challenging scientific endeavours: With at least one academic and five industrial partners, a K2-Centre obtains up to $55 \%$ support over a 10 -year period, with a maximum of 5 million EUR per year. Hereby, international significance and visibility of the research is demanded. As of 2012, about 25 K-Projects, 16 K1-Centres, and five K2-Centres have been funded through the Austrian competence centres programme [44].

A recent ex-post evaluation of the Austrian competence centres programme hints at the remarkable increase in science-industry relations in Austria beginning from the late 1990s [43]. However, the study is quite frank about the potential contribution of the competence centres programme to the performance of the innovation system: The respective shares are less than $2 \%$ of total public and $0.9 \%$ of total private expenditures on $\mathrm{R} \& \mathrm{D}$, which puts the role of the competence centres programme, at least in terms of financial contribution, into perspective. Nevertheless, the evaluation concedes a structuring effect on public funding and on intensifying collaboration between industry and academia. A core question that remains from this evaluation project is, what would be the right level of public investment, so that an effect of the competence centres programme could emerge on the system level. This issue can obviously not be addressed by standard evaluation since there is no counterfactual history. This is where our agent-based simulation comes in, and is able to contribute to the discussion by exploring different scenarios in the given innovation system.

\section{The model}

In our modelling approach, we seek to estimate effects of regional networking induced by competence centres on the innovative performance of the Vienna life sciences innovation system. Building on the SKIN model - Simulating Knowledge Dynamics in Innovation Networks [37, $1,19]$, we develop an empirically guided, case-specific agent-based model to address this question. In this model, companies, universities, public research and other relevant research organizations are treated as heterogeneous agents that make investment decisions about conducting research, exchange assets with other regional and external agents and produce innovative output.

Referring to the particular empirical case of the life sciences sector in Vienna (Austria), we investigate the long-term impact of a competence centres programme, as a more institutionalized form of regional science-industry cooperation, on innovative behaviour and knowledge-related output. Hereby, we view the life sciences sector as a localised sectoral innovation system [31] and focus on the performance of both the organisations and the innovation system as a whole. In the model, firms, universities, public and private research organisations are heterogeneous agents with individual research strategies that are able to create innovative output.

The model specification used here (Figure 1) builds on an existing agent-based model of the life sciences innovation system in Vienna [25]. Innovative output is modelled as an evolutionary process of generating and recombining knowledge assets among organizations. The model consists of three basic elements:

First, the input side is represented by different kinds of Financial Resources, both Private Funds and Public Funds, enabling and triggering the agents' research activities. Private funds include market revenues, private equity, initial public offerings, bank credits and venture capital. Public funds in the general model include direct funds, both bottom-up (initiated by the organisation) and top-down (initiated by government) as well as indirect funding (tax incentives), and institutional funding (for universities and public research organisations).

Second, the Vienna Life Sciences Innovation System itself - representing the core element of the model - comprises companies, private and public research organizations, universities, universities of applied sciences and government agencies. Organizations are characterized by individual knowledge endowments and are able to invest in isolated as well as collaborative research activities. In effect, the use of public funds reduces the costs of research for organizations. The Knowledge Interactions therein include collaborative research, labour mobility, teaching and lectures, creation of start-ups and spin-offs, licensing, consulting and contract research, as well as extra-regional relations.

The third part of the model describes the Output side of the system, focusing on performance in terms the number of scientific publications, patents and high-tech jobs. Agents produce individual or joint research results, which undergo an evaluation process using fitness functions (see 


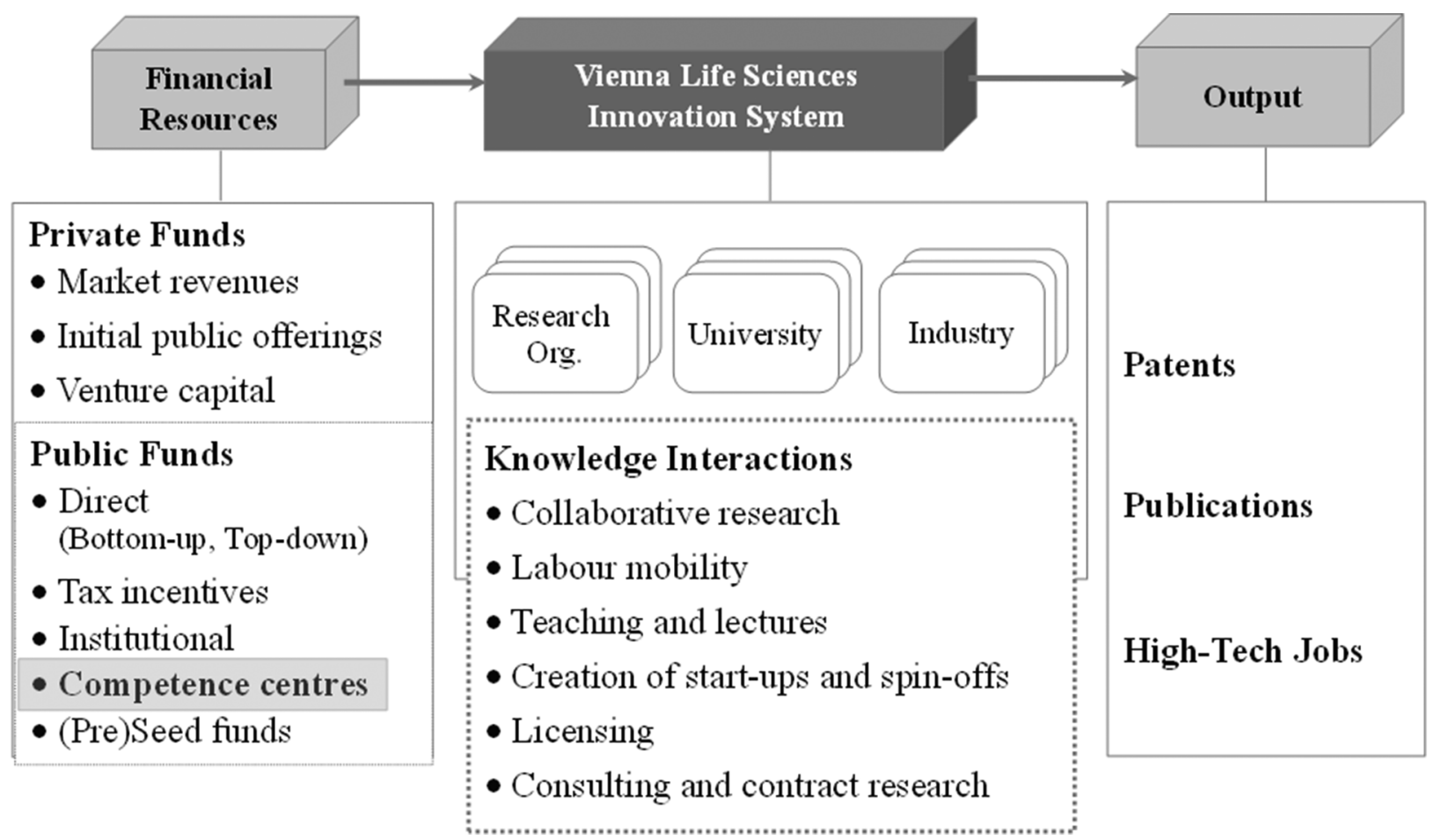

Fig. 1. The agent-based model

[12] for details). Accordingly, a research result of sufficient fitness is attributed the status of a scientific publication or a patent, depending on the dominant orientation of the consortium towards science or industry. Following a positive evaluation, this output feeds back on the involved organizations in terms of an enhanced knowledge endowment and modified attributes, e.g. increased financial stock. Repeatedly unsuccessful organizations deplete their financial resources or forget their knowledge and finally exit the system.

For the purpose of our research interest, we focus on the Austrian competence centres programme COMET as additional element of the input side. Hereby, we include the three classes of competence centres differing in terms of duration and size (K, K1 and $\mathrm{K} 2)$ as described in the previous section. Consortia with industry, university and research organizations can apply for a competence centre. The award of a competence centre grant depends mainly on the consortium composition in terms of the share of science and industry partners and on the quality of proposed research.

\section{Simulation and results}

In our simulation approach, we focus on the long-term effect of the competence centres programme on selected output indicators in the Vienna life sciences innovation system. Thus, we aim at discerning the impact of this specific policy measure against the background of a larger set of public and private funds in the innovation sys- tem. The model was implemented in NetLogo [48] and calibrated with empirical data on organizational characteristics and public funds from 1999 to 2010 .

Agent population at the setup comprises 75 organizations as given by the database on life sciences in the Vienna region. Detailed parameter settings including reference to the data sources are provided in Table 1 to Table 4. Simulations were run for 120 time steps (four time steps per year), representing an observation period of 30 years. All diagrams show mean values over ten simulation runs.

Simulations are based on a standard portfolio of research funds from private and public sources as displayed in Figure 1. The additional effect of funding for competence centres is explored using three different scenarios (see Table 5).

The Reference scenario represents the perpetuation of the empirical calibration period, comprising the standard portfolio of financial resources from Fig. 1 including the competence centres programme. The Termination scenario is characterized by the standard portfolio with the competence centres programme terminated after 15 years, while the Alternative scenario denotes the standard portfolio without competence centre funding. At this point, we assume that the availability of competence centre funding is not restricted exogenously, i.e., all consortia that pass the quality evaluation are funded. As a consequence, total demanded public funds emerge endogenously 
Agent parameter settings (all three scenarios)

Table 1

\begin{tabular}{|l|l|}
\hline \multicolumn{1}{|c|}{ Parameter } & \multicolumn{1}{c|}{ Value } \\
\hline $\begin{array}{l}\text { Initial agent } \\
\text { population }\end{array}$ & $\begin{array}{l}75 \text { agents: agent number and structure according to life sciences organisations in the Vienna } \\
\text { region as per 1999 [6] }\end{array}$ \\
\hline $\begin{array}{l}\text { Organization type; } \\
\text { Differentiated org. } \\
\text { type }\end{array}$ & $\begin{array}{l}\text { Industry (SME, LE), University (university, university of applied sciences), Research organization } \\
\text { (public, private): according to life sciences organisations in the Vienna region as per 1999 [6], } \\
\text { Aurelia [10], organisation (business reports, web pages, etc.) }\end{array}$ \\
\hline Research fields & $\begin{array}{l}\text { Calibrated according to life sciences organisations in the Vienna region as per 1999 [6], } \\
\text { complemented by own inquiry }\end{array}$ \\
\hline Core competencies & $\begin{array}{l}\text { Calibrated according to life sciences organisations in the Vienna region as per 1999 [6], } \\
\text { complemented by own inquiry }\end{array}$ \\
\hline Expertise level & Uniform random distribution from 0 to 9 \\
\hline Financial stock & $\begin{array}{l}\text { According to yearly turnover or budget of particular organisations [5, p. 62; 10], organisation } \\
\text { (business reports, web pages, etc.) }\end{array}$ \\
\hline Employees & [6], [10] organisation (business reports, web pages, etc.), complemented by own inquiry \\
\hline Researchers & $6]$, Aurelia [10], organisation (business reports, web pages, etc.), complemented by own inquiry \\
\hline Foundation year & {$[6]$, Aurelia [10] organisation (business reports, web pages, etc.), complemented by own inquiry } \\
\hline Research orientation & $\begin{array}{l}\text { No research, Basic research, Applied research [6], Aurelia [10] organisation (business reports, web } \\
\text { pages, etc.), complemented by own inquiry }\end{array}$ \\
\hline Share of agents & $\begin{array}{l}\text { 67 \% incremental research attitude } \\
49 \% \text { conservative partner search strategy } \\
58 \% \text { imitative collaboration strategy (during cooperation) }\end{array}$ \\
\hline
\end{tabular}

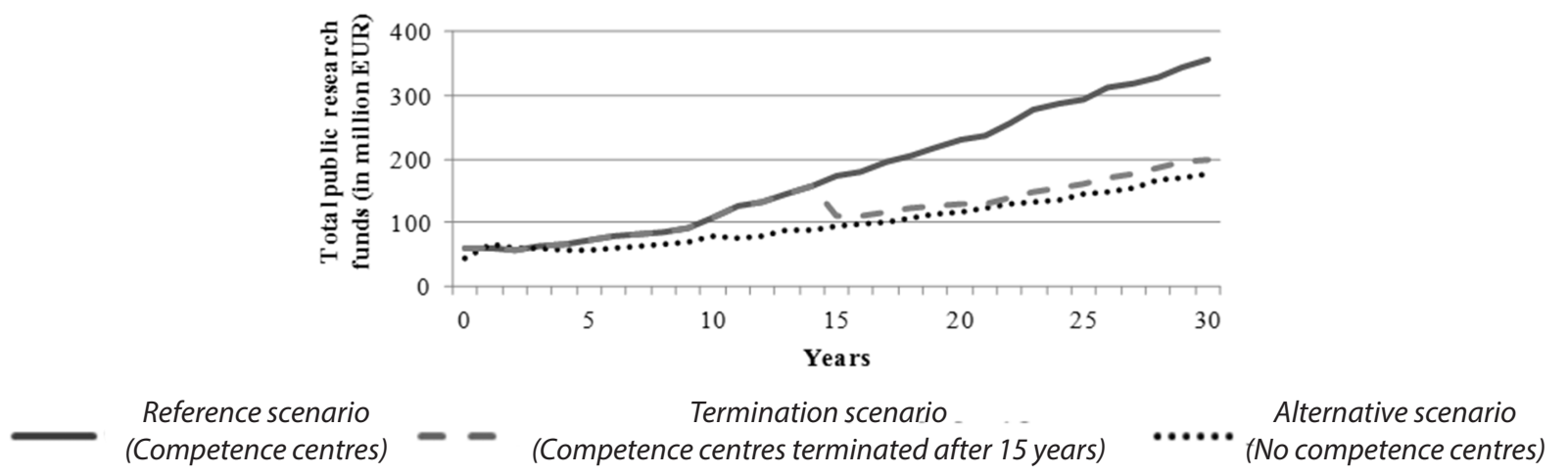

Fig. 2. Total public research funding in the three scenarios

on the input side and are on an increasing path. This idealistic assumption is adopted in order to explore the critical size of a competence centres programme - an issue that was also discussed in the recent evaluation of the competence centres programme in Austria [43, p. 7].

On the input side, the three scenarios differ with respect to the total annual amount of public funds granted (Fig. 2). Obviously, the Reference scenario is the most expensive one in terms of required public funds. On the other hand, we observe that in the Termination scenario funding does not completely descend to the level of the Alternative scenario after the competence centre programme is discontinued. This result might indicate that the competence centres programme has improved the ability of the agents to define high-quality pro- jects, e.g. through newly combined knowledge assets or higher expertise levels. As compared with the Alternative scenario, the system exhibits some memory effect, and alternative public funds can be exploited to a greater extent.

On the output side, we refer to the three hypotheses formulated in Section 2. Generally speaking, the Alternative scenario reflects an increase of the overall population that results from the basic model specification and the given empirical calibration. While this model feature can be discussed per se, the Alternative scenario nevertheless offers a baseline for comparison with the other two scenarios.

Hypothesis 1 states that the SME sector benefits more from the competence centres programme than large firms do. In the simulation, 
System parameter settings and empirical calibration (all three scenarios, per quarter)

\begin{tabular}{|c|c|c|}
\hline Parameter & Value & \\
\hline Random seeds & $20,25,30,40,45,65,70,75,80,90$ & \\
\hline \multicolumn{3}{|l|}{ Receipts and expenditures } \\
\hline \multirow[t]{8}{*}{ Costs of own research } & Research organization agents & $\begin{array}{l}\text { EUR } 100,207 \text { multiplied by } \\
\text { total no. of researchers of the } \\
\text { agent }\end{array}$ \\
\hline & University agents & $\begin{array}{l}\text { EUR 32,702 multiplied by total } \\
\text { no. of researchers of the agent }\end{array}$ \\
\hline & $\begin{array}{l}\text { Research expenses scientific sector and number of } \\
\text { employees } 2007 \text { (Schibany et al. 2010, p. } 143 \text { and p. } \\
\text { 149) }\end{array}$ & \\
\hline & Industry agents & \\
\hline & Total no. of employees $<50$, per quarter & $\begin{array}{l}\text { EUR } 25,543 \text { multiplied by total } \\
\text { no. of researchers of the agent }\end{array}$ \\
\hline & $\begin{array}{l}\text { Total no. of employees } 50-249 \text {, } \\
\text { per quarter }\end{array}$ & $\begin{array}{l}\text { EUR } 44,220 \text { multiplied by total } \\
\text { no. of researchers of the agent }\end{array}$ \\
\hline & Total no. of employees $\geq 250$, per quarter & $\begin{array}{l}\text { EUR } 43,250 \text { multiplied by total } \\
\text { no. of researchers of the agent }\end{array}$ \\
\hline & $\begin{array}{l}\text { Research expenses business sector and number of } \\
\text { employees } 2007 \text { (Schibany et al. 2010, p. 140) }\end{array}$ & \\
\hline $\begin{array}{l}\text { Costs of cooperative research per } \\
\text { partner }\end{array}$ & Uniform random distribution from & EUR 0 to EUR 15,000 \\
\hline Labour mobility & Probability of $3 \%$ & \\
\hline Royalties & Uniform random distribution from & EUR 0 to EUR 600,000 \\
\hline $\begin{array}{l}\text { Remuneration for consulting } \\
\text { projects }\end{array}$ & Uniform random distribution from & EUR 0 to EUR 60,000 \\
\hline $\begin{array}{l}\text { Remuneration for contract } \\
\text { research }\end{array}$ & Uniform random distribution from & EUR 0 to EUR 60,000 \\
\hline $\begin{array}{l}\text { Remuneration for extra-regional } \\
\text { relations }\end{array}$ & Uniform random distribution from & EUR 0 to EUR 10,000 \\
\hline \multirow[t]{2}{*}{ Private equity } & Uniform random distribution from & EUR 0 to EUR 25,000 \\
\hline & Probability per quarter of [41] & $5 \%$ \\
\hline Bank credit & Uniform random distribution from & EUR 0 to EUR 100,000 \\
\hline \multirow[t]{6}{*}{ Initial financial stock of start-ups } & SME: Uniform random distribution from & EUR 0 to EUR 70,000 \\
\hline & $\begin{array}{l}\text { minimum nominal capital for Austrian } \mathrm{GmbH} \text { : } \\
\text { EUR } 35,000[20]\end{array}$ & \\
\hline & LE: Uniform random distribution from & EUR 0 to EUR 100,000 \\
\hline & $\begin{array}{l}\text { minimum share capital for Austrian AG: } \\
\text { EUR 50,000 [2] }\end{array}$ & \\
\hline & University: Uniform random distribution from & EUR 0 to EUR 20,000 \\
\hline & Research org.: Uniform random distribution from & EUR 0 to EUR 20,000 \\
\hline Revenue per sold innovation & Uniform random distribution from & EUR 0 to EUR 100,000 \\
\hline Venture capital & $\begin{array}{l}\text { Venture capital is limited to investment in seed, } \\
\text { start-up, early development and expansion stages. } \\
\text { Later stage replacement and buy-out investments } \\
\text { are excluded. Venture capital investment data for the } \\
\text { life sciences for 2007, Average size per investment } \\
\text { per year: USD 791,600: as of } 20 \text { January 2012: EUR } \\
611,524 \text { [34, p.96 and p.101] }\end{array}$ & \\
\hline Cash flow from issued shares & EUR 100,000 & \\
\hline SMEs go public & Probability of $0.1875 \%$ (Schibany et al. 2010, p. 141) & \\
\hline
\end{tabular}


Switches to determine the agents' option for action (all three scenarios)

\begin{tabular}{|l|c|}
\hline \multicolumn{1}{|c|}{ Parameter } & Parameter settings \\
\hline Private funds & ON \\
\hline Market revenues & ON \\
\hline Private equity & ON \\
\hline Initial public offering & ON \\
\hline Bank credits & ON \\
\hline Venture capital & ON \\
\hline Knowledge interactions & ON \\
\hline Collaborative research & ON \\
\hline Labour mobility & ON \\
\hline Teaching and lectures & ON \\
\hline Creation of start-ups and spin-offs & ON \\
\hline Licensing & ON \\
\hline Consulting and contract research & ON \\
\hline Extra-regional relations & ON \\
\hline Agent exits & \\
\hline Exit due to bankruptcy & \\
\hline Exit because expertise is forgotten & \\
\hline
\end{tabular}

Empirical calibration of government funds in the three scenarios

\begin{tabular}{|c|c|c|c|c|}
\hline Parameter & Parameter settings & \begin{tabular}{|c|} 
Reference \\
scenario
\end{tabular} & $\begin{array}{l}\text { Termination } \\
\text { scenario }\end{array}$ & $\begin{array}{l}\text { Alternative } \\
\text { scenario }\end{array}$ \\
\hline $\begin{array}{l}\text { Direct } \\
\text { funding }\end{array}$ & $\begin{array}{l}\text { Bottom-up direct funding: } \\
\text { Share of funded project expenses: } \\
\text { Uniform random distribution from } 0 \% \text { to } 50 \% \\
\text { Top-down direct funding: ZIT Calls: calibrated volume and } \\
\text { probability referring to particular research fields and core } \\
\text { competencies [45] }\end{array}$ & $\mathrm{ON}$ & $\mathrm{ON}$ & $\mathrm{ON}$ \\
\hline $\begin{array}{l}\text { Indirect } \\
\text { funding }\end{array}$ & $\begin{array}{l}\text { Depends on research expenses, } 10 \% \text { research premium to } \\
\text { industry agents, ceiling amount: } 100,000 \text { per agent per year [27] }\end{array}$ & $\mathrm{ON}$ & $\mathrm{ON}$ & $\mathrm{ON}$ \\
\hline $\begin{array}{l}\text { Institutio- } \\
\text { nal funding }\end{array}$ & $\begin{array}{l}\text { Institutional funding volume per quarter: } \\
\text { Uniform random distribution from } 0 \text { to } 86,953 \text { [5, p. 62] }\end{array}$ & $\mathrm{ON}$ & $\mathrm{ON}$ & $\mathrm{ON}$ \\
\hline $\begin{array}{l}\text { Creation of } \\
\text { competence } \\
\text { centres }\end{array}$ & $\begin{array}{l}\text { Calibrated volume, probability and duration, unlimited total } \\
\text { funds (i.e. unlimited total number of competence centres) (FFG } \\
\text { criteria: K (p.38), K1 (p. 22), K2 (p. 12): [44] }\end{array}$ & $\mathrm{ON}$ & $\begin{array}{l}\text { Years 1-15: ON, } \\
\text { Years 16-30: } \\
\text { OFF }\end{array}$ & OFF \\
\hline $\begin{array}{l}\text { (Pre) Seed } \\
\text { funding }\end{array}$ & $\begin{array}{l}\text { Calibrated volume of (pre)seed funds; Average volume per } \\
\text { funded project = 484,800; Uniform random distribution from } 0 \\
\text { to } 947,000[4]\end{array}$ & $\mathrm{ON}$ & $\mathrm{ON}$ & $\mathrm{ON}$ \\
\hline
\end{tabular}

The simulation scenarios at a glance

\begin{tabular}{|l|l|l|}
\hline \multicolumn{1}{|c|}{ Scenarios } & \multicolumn{1}{|c|}{ Implemented policy measures } & \multicolumn{1}{c|}{ Legend } \\
\hline $\begin{array}{l}\text { Reference } \\
\text { scenario }\end{array}$ & $\begin{array}{l}\text { Competence centres programme, Direct funding, Indirect } \\
\text { funding, Institutional funding, (Pre)Seed funding }\end{array}$ & $\begin{array}{l}\text { Competence centres programme } \\
\text { (perpetuated) }\end{array}$ \\
\hline $\begin{array}{l}\text { Termination } \\
\text { scenario }\end{array}$ & $\begin{array}{l}\text { Competence centres programme (Year 1-15), Direct } \\
\text { funding, Indirect funding, Institutional funding, (Pre)Seed } \\
\text { funding }\end{array}$ & $\begin{array}{l}\text { Competence centres programme } \\
\text { (terminated after 15 years) }\end{array}$ \\
\hline $\begin{array}{l}\text { Alternative } \\
\text { scenario }\end{array}$ & $\begin{array}{l}\text { Direct funding, Indirect funding, Institutional funding, } \\
\text { (Pre)Seed funding }\end{array}$ & No competence centres \\
\hline
\end{tabular}






Fig. 3. Number of agents in the population (by agent type)

a) Patents

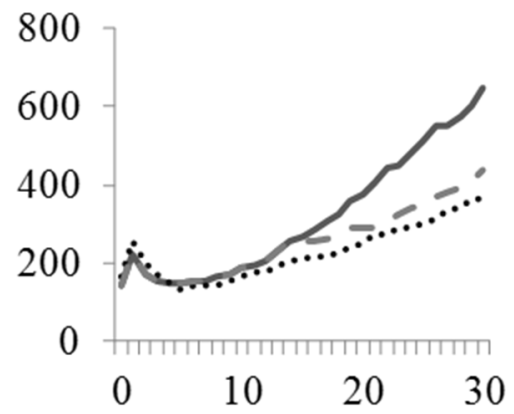

Reference scenario

- (Competence centres) b) Publications

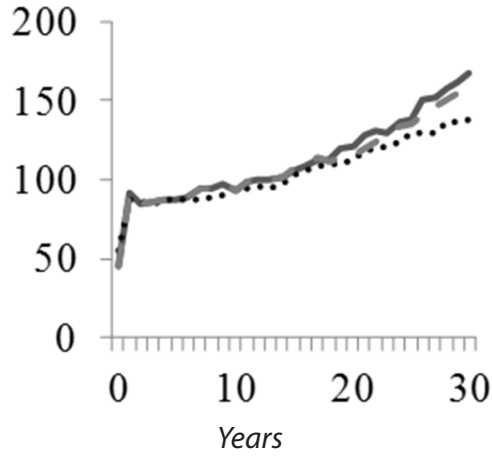

Termination scenario

(Competence centres terminated after 15 years)

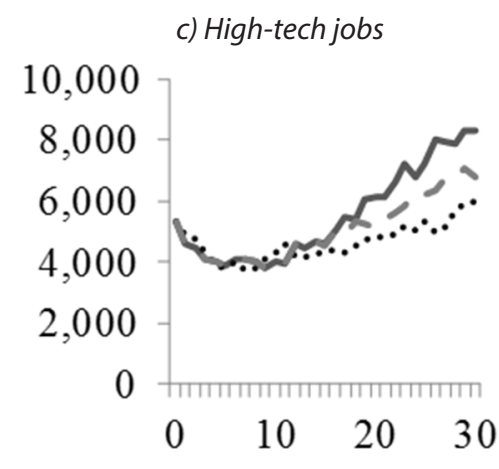

Alternative scenario (No competence centres)

Fig. 4. Selected performance indicators by scenarios

agent demographics reveal quite different evolution for different agent types (Fig. 3). All three scenarios are characterized by a positive evolution of small and medium sized enterprises, but only in the long run. Especially in the Reference scenario with continuous funding for competence centres, the SME sector benefits regarding the number of firms. This may result from reduced bankruptcy exits, but also from competitive advantages due to greater heterogeneity of the knowledge pool. To a lesser extent, research organizations exhibit a positive effect from competence centres in terms of agent numbers. In comparison, the large enterprise and the university sectors do not exhibit increased growth rates. Moreover, the number of high-tech jobs (Fig. 4) shows a considerable impact from the competence centres programme, which is also partly due to the growing number of SMEs in the system. Thus, Hypothesis 1 is supported by the model, stating that competence centres have a positive long-term impact on the size of the SME sector, while the large enterprise sector is weakly affected.
Hypothesis 2 refers to the ability of competence centres to boost patenting activity in the region. Regarding the number of patents, the model produces differing evolutionary paths in each of the scenarios (Fig. 4a). While the Alternative scenario (standard portfolio without competence centres) exhibits a moderate growth, the Reference scenario with competence centres leads to a considerable increase in patenting. In the Termination scenario, patenting returns to the slower pace of the Alternative scenario quickly, when competence centre funding stops (after 15 years). Again, a memory effect can be identified. The model thus predicts that competence centres have an impact on patenting activities especially in the long run.

Hypothesis 3 is related to the ability of competence centres to increase scientific publication activity in the region. Simulation results reveal little difference between the three scenarios in this respect (Fig.4b). This means that competence centres in the model do not evoke large amounts of additional scientific output. This may be attributable to the design of the competence centres 
that foresees a smaller share of academic partners in the consortia, and sees academic partners primarily as sources of knowledge. What is interesting, though, is the fact that in the Termination scenario, scientific publications show almost no downturn after discontinuation of the competence centres programme and remain sustainably at the pace of the Reference scenario.

\section{Conclusion}

In this paper, we have presented an agentbased model of the Vienna life sciences innovation system, and have simulated long-term effects of a competence centres programme - regarded as a policy induced realisation of geographically localised R\&D networks - on regional knowledge production. Our explorative study intends to suggest potential ways how agent-based models could shed light on the debate in theoretical and empirical literature how policy induced local and global networking may affect the innovative performance of regional innovation systems.

In a policy context, such simulation approaches show the potential to support the ex-ante impact assessment of intended policy measures, such as the competence centre programme. Several of the existing competence centres in Austria are in the life sciences field; current programme evaluations have triggered lively debates about their impact. Facing the vagueness of empirical evidence and the open issue of learning from ex-post evaluations, we adopt an ex-ante perspective and use agent-based simulation for experimenting with alternative scenarios. Our study explores potential effects of competence centres on selected output indicators, namely scientific publications, patents and high-tech jobs by comparing three different scenarios: (i) A Reference scenario, where competence centres are continuously funded for 30 years, (ii) a Termination scenario, where funds for competence centres are terminated after 15 years and (iii) an Alternative scenario, where no competence centres exist at all.

The model shows that small and medium sized enterprises benefit more than all other agent types from the competence centres programme. This is represented by a continuous increase referring to the number of small and medium sized enterprises in the agent population during the Reference scenario, particularly in the long run. We assume this is due to an augmented heterogeneity in the joint knowledge pool and to a reduced number of SMEs that have to exit the system due to bankruptcy. The simulation results show only minimal effects of competence centres on the large enterprise sector.
In terms of patenting activities in a region, we find a strong growth of the number of patents during the last 15 years of the Reference scenario, where competence centres are funded throughout the whole 30-years-period. A memory effect is observed, i.e. if funding is stopped after 15 years agents are still able to benefit from raised expertise levels and thus patent and publish more than if competence centres have never existed. Referring to the publication activity of the agents in the region, the simulation results of the three scenarios reveal only very little differences. In contrast, simulated scientific output is not deeply impacted by the competence centres programme. We presume that this lies in the requirement of competence centres to include a smaller share of academic partners that serve mainly as a source of knowledge.

In terms of the literature investigating the geography of $R \& D$ networks, the results seem to confirm findings in related empirical works that support the complementary character of local and global networking as central factor for regional innovative performance. Competence centres can be seen as important policy induced platform to stimulate such a combination of local and global networking activities. The results point to longterm effects in terms of learning and improved innovative performance of industry, especially the SME sector. Competence centres may indeed facilitate science-industry collaboration and commercialization of scientific results, especially in the long run, through institutionalized and long-term R\&D networks concentrated in space.

It has to be admitted that the general limitations of the present approach are at least twofold. First, the trade-off between an account of the complexity of the innovation system on the one hand and the quest for analytic clarity and simplicity on the other, will limit the prediction capability of policy-related agent-based models in quantitative terms. Although agent-based modelling gains ground in social sciences and economics, the question regarding when we can consider a model as reliable - and empirically validated - is still not fully solved. Second, accounting for novelty in the presented knowledge generation model is restricted to re-combinations of existing knowledge endowments, which may limit the coverage of radical innovation. Evaluating the quality of the produced knowledge without reference to semantics, remains another fundamental challenge, which we have addressed by using fitness functions.

Future research will introduce statistical analysis for interpretation of the simulation results, 
and explore alternative fitness functions that are used for evaluating the simulated knowledge outputs. With regard to the spatial dimension of the model, a more explicit account of extra-regional $\mathrm{R} \& \mathrm{D}$ networks needs to be considered. Moreover, other sectors with different knowledge production regimes like machinery, information and commu- nication technology, energy and others will help to endorse our methodological approach. Hereby, the relevance of the simulation results will be improved by involving policymakers, thus relying on the companion-modelling approach [8], also referred to as expert validation.

This paper reports research results carried out in the framework of the Innovation Economics Vienna - Knowledge and Talent Development Program. The first author gratefully acknowledges the scholarship provided by this program. Both authors gratefully acknowledge support from the Austrian Science Fund (FWF): [I 886-G11] within the project "Innovation networks for regional development - An agent-based simulation approach". Furthermore, the authors would like to thank Manfred M. Fischer, Andreas Pyka and Michael Barber for valuable comments and discussions.

\section{References}

1. Ahrweiler P., Pyka A., Gilbert, N. (2004). Simulating knowledge dynamics in innovation networks (SKIN). 267.

2. AktG Aktiengesetz (1965). Current version, $\$ 7$, Gesetz 9.

3. Asheim B. T., Coenen L. (2005). Knowledge bases and regional innovation systems: Comparing Nordic clusters. [doi: DOI: 10.1016/j.respol.2005.03.013]. Research Policy, 34(8), 1173-1190.

4. Austria Wirtschaftsservice (2011). Seedfinancing Portfolio - Life Sciences.

5. Austrian Federal Ministry for Science and Research (2008). University report 2008. 2nd corrected edition.

6. Austrian Life Sciences Directory (2009). http://www.lifesciencesdirectory.at/. Accessed 13 June 2009.

7. Austrian Life Sciences Directory (2011). http://www.lifesciencesdirectory.at/. Accessed 3 December 2011.

8. Barreteau O., Antona M., d’Aquino P., Aubert S., Boissau S., Bousquet F., et al. (2003). Our companion modelling approach. Journal of Artificial Societies and Social Simulation, 6((2), 1), doi:http://jasss.soc.surrey.ac.uk/6/2/1.html.

9. Betts J. R., \& Lee C. W. B. (2004). Universities as Drivers of Regional and National Innovation: An Assessment of the Linkages from Universities to Innovation and Economic Growth.

10. Bureau van Dijk (2010). Aurelia company database. http://www.bvdep.com/tw/AURELIA.html. Accessed 8 August 2010.

11. Carter A. P. (2007). Measurement of the clustering and dispersion of innovation. In K. R. Polenske (Ed.), The Economic Geography of Innovation. Cambridge, New York, Melbourne, Madrid, Cape Town, Singapore, São Paulo: Cambridge University Press.

12. Castells M. (2000). The Rise of The Network Society (2nd ed.). Malden: Blackwell Publishers.

13. Cooke P. (2002a). Biotechnology clusters as regional, sectoral innovation systems. International Regional Science Review, $25(1), 8-37$.

14. Cooke P. (2002b). Regional innovation systems: General findings and some new evidence from biotechnology clusters. The Journal of Technology Transfer, 27 (1), 133-145.

15. Fabrizio K. R. (2009). Absorptive capacity and the search for innovation. Research Policy, 38, 255-267.

16. Fischer M. (Ed.). (2006). Innovation, Networks, and Knowledge Spillovers: Selected Essays. Berlin, Heidelberg: Springer.

17. Fischer M., \& Fröhlich J. (2001). Knowledge, complexity and innovation systems: Prologue. In M. Fischer, \& J. Fröhlich (Eds.), Knowledge, Complexity and Innovation Systems (pp. 1-17). Berlin, Heidelberg and New York: Springer.

18. Fischer M. M. (2003). The new economy and networking. In D. Jones (Ed.), New Economy Handbook (pp. 343-367). San Diego, California: Academic Press, Elsevier.

19. Gilbert N., Pyka A., \& Ahrweiler P. (2001). Innovation networks - a simulation approach. Journal of Artificial Societies and Social Simulation, 4(3), 8).

20. GmbHG (2012). Gesetz über Gesellschaften mit beschränkter Haftung. $₫ 6$ Abs. 1 Satz 2 GmbHG.

21. Graf H. (2006). Networks in the Innovation Process - Local and Regional Interactions. Cheltenham, etc.: Edward Elgar Publishing.

22. IMP (2011). Research Institute of Molecular Pathology: IMP. http://www.imp.ac.at/the-imp/history/. Accessed 25 January 2011.

23. Jaffe A. B. (1989). Real effects of academic research. The AmericanEconomic Review, 79, 957-970.

24. Karlsson C., Andersson A., Cheshire P., \& Stough R. (2009). Innovation, Dynamic Regions and Regional Dynamics. In C. Karlsson, A. E. Andersson, P. C. Cheshire, \& R. R. D. Stough (Eds.), New Directions in Regional Economic Development (pp. 1-33). Northampton, MA, USA: Edward Elgar.

25. Korber M. (2012). Agent-Based Modelling of Complexity in Life Sciences - With a special emphasis on the impact of public funding on research activities. Book series of the Innovation Economics Vienna - Knowledge and Talent Development Programme PhD- \& Master-Theses, Doctoral work, Vol. 16, AIT Austrian Institute of Technology GmbH, Vienna University of Economics and Business, PhD- \& Master-Theses Series 16.

26. Lambooy J. G. (2004). The Transmission of Knowledge, Emerging Networks, and the Role of Universities: An Evolutionary Approach.

27. Legal Information System of the Republic of Austria (RIS) 2012 Einkommensteuergesetz EStG 1988, Prämien für Forschung und Bildung (Forschungsprämie, Bildungsprämie). \$108c.

28. Liebeskind J., Oliver A., Zucker L., \& Brewer M. (1996). Social networks, learning, and flexibility: sourcing scientific knowledge in new biotechnology firms. Organization Science, 3: , 783-831. 
29. LISAvienna (2011a). 1. Oktober 2011 - LISA VR wird zu LISAvienna. http://www.lisavr.at/siteLayout.php. Accessed 25 November 2011.

30. LISAvienna (2011b). Vienna Life Science Report: Sector Survey: Facts and Directory 2011/2012. Vienna and Berlin: LISAvienna, Life Science Austria, Biocom AG.

31. Malerba F. (2002). Sectoral systems of innovation and production. Research Policy, 31((2)), 247-264.

32. McMillan G., Narin F., \& Deeds D. (2000). An analysis of the critical role of public science in innovation: The case of biotechnology. Research Policy, 29((1)), 1-8.

33. OECD (2004). Public-Private Partnerships for Research and Innovation: An Evaluation of the Austrian Experience. Paris.

34. OECD (2009). OECD Biotechnology Statistics - 2009. Paris: OECD.

35. Powell W., White D., Koput K., \& Owen-Smith J. (2005). Network dynamics and field evolution: The growth of inter-organizational collaboration in the life sciences. American Journal of Sociology, 110((4)), 1132-1205.

36. Pyka A. (2002). Innovation networks in economics: from the incentive-based to the knowledge-based approaches. European Journal of Innovation Management, 5(3), 152-163.

37. Pyka A., \& Saviotti P. (2002). Innovation networks in the biotechnology-based sectors. In A. Pyka, \& G. Küppers (Eds.), Innovation Networks: Theory and Practice (pp. 75-107). Cheltenham and Northampton, MA: Edward Elgar.

38. Reiss T., Lacasa I. D., Mangematin V., Corolleur F., Enzing C., van der Giessen A., et al. (2005). Benchmarking of public biotechnology policy. Fraunhofer Institute Systems and Innovation Research, European Commission Enterprise Directorate General, , Final report.

39. Saxenian, A. (1991). The origins and dynamics of production networks in Silicon Valley. [doi: DOI: 10.1016/00487333(91)90067-Z]. Research Policy, 20(5), 423-437.

40. Schartinger, D., Rammer, C., Fischer, M., \& Fröhlich, J. (2002). Knowledge interactions between universities and industry in Austria: Sectoral patterns and determinants. Research Policy, 31(3), 303-328.

41. Schibany, A., Berger, M., Buchinger, E., Dachs, B., Dinges, M., Ecker, B., et al. (2010). Life Sciences in Österreich. Austrian Research and Technology Report 2010, , pp. 138-165.

42. Schibany, A., Berger, M., Dachs, B., Falk, R., Gassler, H., Huber, P., et al. (2009). The Austrian Innovation System: Appraisals and Perspectives. Austrian Research and Technology Report 2009, pp. 60-84.

43. Schibany, A., Dinges, M., Reiner, C., Reidl, S., Hofer, R., Marbler, F., et al. (2013). Ex-post Evaluierung der Kompetenzzentrenprogramme Kplus und Kind/net. Preliminary final report.

44. The Austrian Research Promotion Agency - FFG (2010). FFG Fokus: Kompetenz und Exzellenz — Die Comet-Zentren und-Projekte: Österreichs Flaggschiffe in der Spitzenforschung. Österreichische Forschungsförderungsgesellschaft mbH, 1st edition.

45. The Technology Agency of the City of Vienna - ZIT (2010). Call Archive. http://www.zit.co.at/en/funding/current-calls/ call-archive.html. Accessed 10 March 20102010.

46. Uzzi, B. (1997). Social structure and competition in interfirm networks: the paradox of embeddedness. Administrative Science Quarterly, 42, 35-67.

47. Van Looy, B., Callaert, J., \& Debackere, K. (2006). Publication and patent behavior of academic researchers: Conflicting, reinforcing or merely co-existing? Research Policy, 35(4), 596-608, doi:http://dx.doi.org/10.1016/j.respol.2006.02.003.

48. Wilensky, U. (1999). NetLogo. http://ccl.northwestern.edu/netlogo. Accessed 2 March 2012.

49. WWTF (2011). Programme \& Ausschreibungen - Life Sciences. http://www.wwtf.at/programmes/ls/. Accessed 15 June 2011.

\section{Information about the authors}

Korber Manuela (Vienna, Austria) — PhD, Junior Scientist, AIT Austrian Institute of Technology GmbH, Innovation Systems Department, Research, Technology \& Innovation Policy (Donau-City-Straße 1, 1220 Vienna, Austria, e-mail: manuela.korber@ait. ac.at, manuelakorber@yahoo.com).

Paier Manfred (Vienna, Austria) - Mag., Scientist, AIT Austrian Institute of Technology GmbH, Innovation Systems Department, Research, Technology \& Innovation Policy (Donau-City-Straße 1, 1220 Vienna, Austria, e-mail: manfred.paier@ait. ac.at). 